Artigo Original

\title{
O estilo motivacional de professores de Educação Física
}

\author{
Daniela Schwabe Minelli ${ }^{12}$ \\ Glauce Yara do Nascimento 123 \\ Lenamar Fiorese Vieira ${ }^{4}$ \\ leda Parra Barbosa-Rinaldi ${ }^{5}$ \\ ${ }^{1}$ Mestranda do programa de pós-graduação associado em Educação Física/UEM/UEL \\ da UEL, PR, Brasil \\ ${ }^{2}$ Grupo de Estudos sobre a Intervenção do Profissional de Educação Física-UEL, PR, \\ Brasil \\ 3 Bolsista da Fundação Araucária \\ ${ }^{4}$ Departamento de Educação Física da Universidade Estadual de Maringá e Programa de \\ Estudos para o Desenvolvimento do Esporte - Pró-Esporte, Maringá, PR, Brasil \\ ${ }^{5}$ Departamento de Educação Física da Universidade Estadual de Maringá \\ Grupo de Pesquisa Gímnica: formação, intervenção e escola da UEM, Maringá, PR, \\ Brasil /CNPq
}

\begin{abstract}
Resumo: $O$ presente estudo teve como objetivo identificar qual o estilo motivacional adotado por professores de educação física escolar, exclusivamente no que se refere à autonomia. A pesquisa de caráter descritivo-exploratório contou com a participação de 16 professores atuantes em escolas do município de Cambé, norte do Paraná. Os dados foram coletados por meio do instrumento "Problemas na escola", composto por oito vinhetas que representam cenários comuns às escolas, seguidas de quatro afirmações que devem ser avaliada numa escala de Likert. Cada uma das quatro situações-respostas corresponde a um estilo motivacional adotado, que varia de altamente controlador até altamente promotor de autonomia. Os resultados mostraram que o estilo motivacional altamente promotor de autonomia foi 0 mais adotado pelos participantes da pesquisa, podendo assim, representar uma prática docente na educação física escolar que promova efetivamente a aprendizagem e, uma mudança efetiva no comportamento dos estudantes.
\end{abstract}

Palavras-chave: Autonomia. Motivação. Docente. Escola.

\section{The motivational style of Physical Education teachers}

\begin{abstract}
The study aimed to identify the motivational style adopted by teachers of Physical Education School, only with regard to autonomy. The research was a descriptive exploratory with the participation of 16 teachers working in public schools in Cambé, north of Paraná. Data were collected via the instrument "Problems in Schools", composed of eight vignettes that represent common scenarios for schools followed by four statements to be assessed on a Likert scale. Each of the four-response situations corresponds to a motivational style adopted, ranging from highly controlling to highly autonomy. The results showed that the promoter highly motivational style of autonomy was the most frequently adopted by the participants and may therefore represent a teaching practice in physical education to promote effective learning and an effective change in the behavior of students.
\end{abstract}

Key Words: Autonomy. Motivation. Teaching. School.

\section{Introdução}

A aprendizagem envolve a integração de fatores contextuais e internos do aluno e, no ambiente escolar, esses elementos exercem uma influência maior no processo, pois eles podem favorecer ou afetar de maneira negativa 0 processo de aprender. Sendo assim, a motivação dos estudantes aparece como um dos grandes desafios enfrentados pelos educadores e, esse tem sido um dos motivos que faz com que as práticas pedagógicas no ensino formal necessitem ser constantemente (re) pensadas.

A disciplina da educação física como componente curricular obrigatório da Educação Básica assume importantes funções na sociedade contemporânea, entre elas: introduzir e integrar o aluno na cultura corporal de movimento (BETTI; ZULIANE, 2002; DARIDO, 2004) e proporcionar a crianças e adolescentes vivências motoras que podem favorecer, ao longo do tempo, a adoção de um estilo de vida fisicamente 
ativo (KOKA; HEIN, 2003; STANDAGE; DUDA; NTOUMANIS, 2003).

Desse modo, motivar os estudantes nas aulas de educação física, especificamente com relação à sua motivação intrínseca, representa um grande desafio, sobretudo porque a qualidade da interação entre professores e alunos, influenciada em grande parte pelo estilo motivacional dos primeiros, revela-se a fonte principal de satisfação ou frustração dos estudantes (GUIMARÃES; BORUCHOVITCH, 2004).

Nesse sentido, algumas pesquisas (NTOUMANIS, 2005; VIERLING; STANDAGE; TREASURE, 2007; TAYLOR; NTOUMANIS; STANDAGE, 2008; GUIMARÃES, 2005) ressaltam que a motivação em contextos escolares tem sido avaliada como um fator determinante do nível de qualidade da aprendizagem e do desempenho escolar. $O$ indivíduo motivado reage de forma diferenciada, se envolvendo no processo, engajando-se e persistindo em tarefas desafiadoras, despendendo esforços, usando estratégias adequadas, buscando desenvolver novas habilidades de compreensão e domínio além de demonstrar maior entusiasmo no envolvimento de suas atividades (GUIMARÃES; BORUCHOVITCH, 2004). Outrossim, indivíduos intrinsecamente motivados apresentarão atitudes positivas em relação a uma determinada prática resultando em maiores chances de se manterem engajados na atividade (NTOUMANIS, 2001).

$\mathrm{Na}$ tentativa de compreender como os determinantes motivacionais influenciam as atitudes e os comportamentos dos indivíduos e, também de revelar como 0 ambiente pode interferir no comportamento humano, foi desenvolvida a teoria da autodeterminação (DECl; RYAN, 1985). A teoria destaca que a motivação deve ser compreendida a partir de um continuum que tem em um extremo a motivação intrínseca e, no outro, a amotivação. No entanto, entre esses dois pólos ainda existem quatro formas auto-reguladoras de motivação extrínseca: regulação integrada, regulação identificada, regulação introjetada e regulação externa (Figura 1).

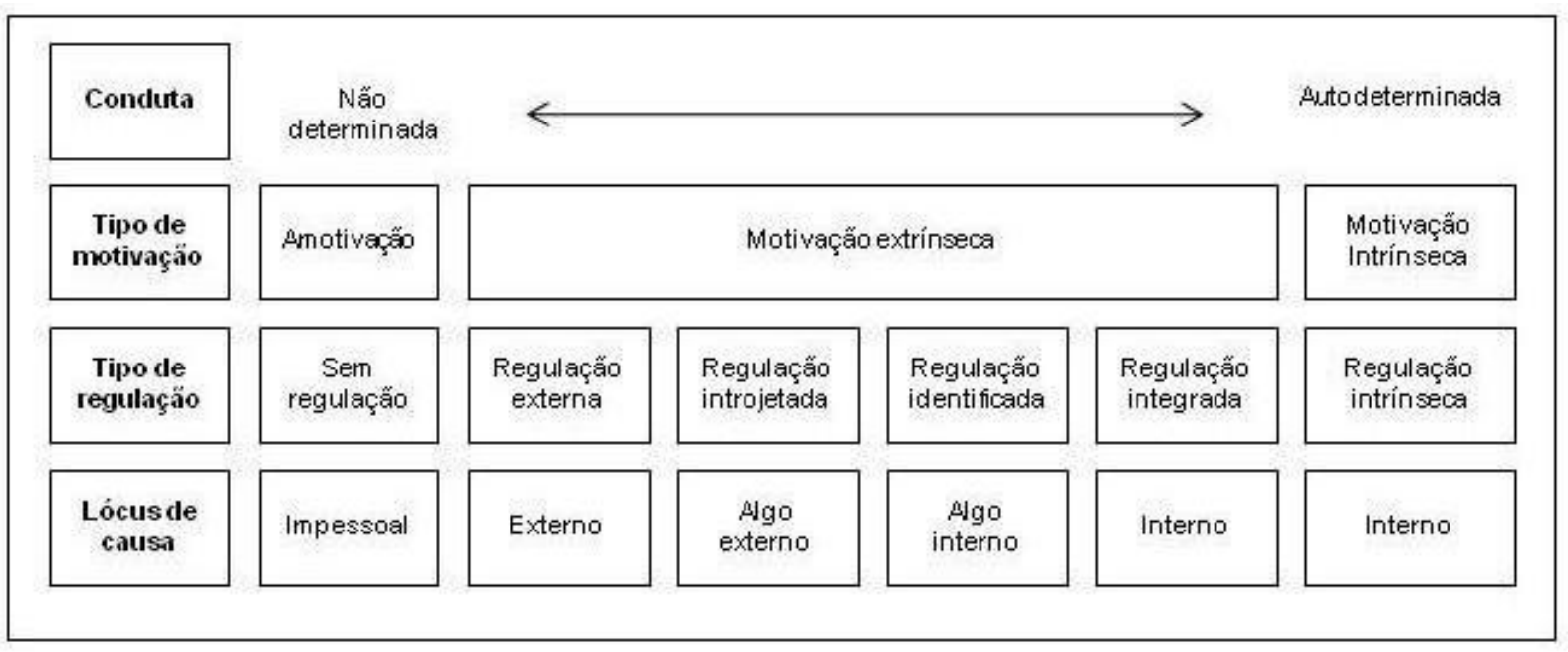

Figura1. Continuum da autodeterminação indicando os tipos de motivações, seus estilos regulatórios e o lócus de causa (DECl e RYAN, 2000).

A motivação intrínseca ou autodeterminada é o melhor estado ou condição psicológica, pois nesse estágio o indivíduo se reconhece como autor de suas ações e verdadeiramente engajado em uma atividade. Por exemplo, uma pessoa realiza atividade física regular porque tem consciência da importância e dos benefícios para sua saúde.

$\mathrm{Na}$ regulação integrada, a forma mais autônoma da regulação externa do comportamento, o indivíduo tem consciência dos seus atos e toma decisões de acordo com suas escolhas pessoais (FERNANDES; VANSCONCELOS-RAPOSO, 2005). Na regulação identificada os indivíduos adotam certo tipo de comportamento visando se beneficiar com a atividade, não buscando o prazer e satisfação inerentes à própria atividade (NTOUMANIS, 2001, 2005). Por exemplo, muitas pessoas praticam atividade física para manter-se em forma (fins estéticos). 
Já na regulação introjetada existe tanto um controle externo como uma situação de conflito interno que direcionam o comportamento do indivíduo: prevalência de culpa ou ansiedade (interno) caso não realize a prática de exercícios físicos regulamente, como indicado para a saúde (externo) (STANDAGE; DUDA, NTOUMANIS, 2003).

A forma mais básica da motivação extrínseca é a regulação externa, sendo designada como uma forma não autônoma de motivação. O comportamento é apresentado por recompensas oferecidas a um indivíduo ou por ameaças e punições (DECl e RYAN, 1985). Por exemplo, o sujeito permanece em um determinado esporte pelas recompensas financeiras ou um professor oferece notas adicionais se os alunos se comportarem da maneira que ele deseja, podendo puní-los caso contrário.

Por fim, a amotivação diz respeito à ausência de intenção ou pensamento em relação a qualquer comportamento. Nesse caso, 0 indivíduo percebe a inexistência de contingências entre as ações e os resultados, não existindo razão para continuar uma determinada atividade (BIDDLE et al., 1999).

Além disso, a teoria da autodeterminação aborda a personalidade e a motivação humana focalizando que desde o nascimento, a criança possui predisposição inata para aprendizagem e, que o ambiente pode favorecer ou diminuir essa tendência, na medida em que nutre ou frustra três necessidades psicológicas básicas e universais: a autonomia, a competência e a necessidade de estabelecer vínculos sociais (DECl; RYAN, 1985, 2000).

A autonomia refere-se à capacidade do indivíduo de autogovernar-se, sendo o seu comportamento originado e regulado por suas próprias ações. A competência diz respeito à capacidade de agir satisfatoriamente em uma determinada situação, apresentando atitudes de domínio frente uma tarefa desafiadora. Por fim, o estabelecimento de vínculos representa a necessidade dos seres humanos de sentirem-se aceitos e reconhecidos socialmente (STANDAGE; DUDA; NTOUMANIS, 2003; GUIMARÃES; BORUCHOVITCH, 2004; FERNANDES; VASCONCELOS-RAPOSO; 2005; MURCIA; COLL, 2006; WILSON et al, 2006).

Embora, inicialmente, acreditava-se que a competência representava a necessidade psicológica de maior importância (GUIMARÃES; BORUCHOVITCH, 2004), a partir da elaboração da teoria da autodeterminação (DECl; RYAN, 1985), atribui-se que a interação entre esses três elementos passa a ser um fator fundamental para compreender o comportamento autodeterminado. Em outras palavras, a percepção de autonomia, isto é, o senso de liberdade e responsabilidade individual, associada à maneira como o indivíduo percebe e interage com 0 ambiente, podem fortalecer ou enfraquecer a sua percepção de competência.

Dessa forma, enfocamos nesse estudo, especificamente, a necessidade de autonomia, tendo em vista que ambientes educativos promotores de autonomia contribuem e reforçam - desenvolvimento de comportamentos intrinsecamente motivados. Por outro lado, em ambientes controladores os indivíduos sentem-se como "marionetes" controlados por forças externas, exigindo, muitas vezes, formas de motivação extrínseca, baseadas em um sistema de recompensas e punições (STANDAGE; DUDA; NTOUMANIS, 2003; GUIMARÃES; BORUCHOVITCH, 2004).

Nesse sentido, para que 0 processo de ensino-aprendizagem obtenha resultados positivos, torna-se necessário que os professores adotem posturas e estratégias que enfatizem um ambiente promotor de autonomia. Assim, chegamos ao seguinte problema: qual o estilo motivacional adotado por professores de educação física? O principal objetivo dessa pesquisa foi analisar qual o estilo motivacional adotado por professores de educação física atuantes na educação infantil e no primeiro ciclo do ensino fundamental.

Como o contexto no qual o indivíduo está inserido pode nutrir ou prejudicar suas formas de comportamento autodeterminadas, investigar qual o estilo motivacional adotado por professores em suas aulas torna-se uma ferramenta imprescindível, pois segundo Deci e Ryan (2000) e Ntoumanis (2005), ele representa um dos elementos que tem influência direta na qualidade do envolvimento dos estudantes na tarefa e no processo de tomada de decisão em comportamentos futuros.

Portanto, ao colocarmos o professor de educação física no centro do debate, esperamos contribuir com as discussões existentes acerca da atuação do professor na promoção da motivação intrínseca e, também, contribuir com a possibilidade de novas perspectivas à ação docente em nosso país, já que a produção científica sobre 0 papel da motivação em contextos educativos no Brasil ainda é incipiente 
(GUIMARÃES; BORUCHOVITCH, 2004).

\section{Metodologia}

A presente pesquisa, de natureza descritivoexploratória teve como objetivo identificar e analisar o estilo motivacional adotado por professores de educação física atuantes na educação infantil e no primeiro ciclo do ensino fundamental. Participaram do estudo 16 professores de educação física da rede municipal de ensino de Cambé (Paraná). O convite aconteceu durante uma reunião na Secretaria de Educação do município e a adesão à pesquisa se deu de forma voluntária.

$\begin{array}{cccccc}\text { IDADE (anos) } & \mathbf{2 0 - 3 0} & \mathbf{3 0 - 4 0} & \mathbf{4 0} \text { ou mais } & \text { MÉdIA (anos) } & \text { Total } \\ & 5 & 6 & 5 & 29,81 & 16 \\ \text { ANO DE FORMAÇÃO (por década) } & \mathbf{1 9 8 0} & \mathbf{1 9 9 0} & \mathbf{2 0 0 0} & \text { MÉdIA (anos) } & \text { Total } \\ & 3 & 3 & 7 & 10,07 & 13\end{array}$

Figura 2. Caracterização dos professores pesquisados: idade média (anos) e tempo médio de formação (décadas) dos professores de educação física.

Para avaliar qual o estilo motivacional adotado por professores de educação física foi aplicado o instrumento "Problems in Schools", inicialmente proposto por Deci et al. (1981) e validado para a língua portuguesa por Bzuneck e Guimarães (2007). Originalmente, o questionário busca avaliar o grau de autonomia de professores, designando quatro estilos motivacionais: altamente controlador de autonomia (AC), altamente promotor de autonomia (AA), moderadamente controlador de autonomia (MC) e moderadamente promotor de autonomia (MA). O instrumento consiste de oito vinhetas que descrevem cenários referentes às salas de aula, em que o estudante apresenta algum problema comportamental relacionado à motivação. As vinhetas são seguidas de quatro respostas, as quais devem ser assinaladas pelo professor em uma escala Likert de 1 a 7 , que corresponde a uma situação, julgada por ele, como um comportamento que varia desde muito impróprio até muito apropriado (Anexo 1).

Cada uma das quatro respostas ( $a, b, c$ e d) representam atitudes controladoras ou promotoras de autonomia em alto ou moderado grau, contemplando assim uma das quatro posições no continuum (AC, MC, MA e AA), totalizando assim 32 itens. (Figura 3).

\section{VINHETAS}

$1 \mathrm{C}, 2 \mathrm{~A}, 3 \mathrm{~B}, 4 \mathrm{D}, 5 \mathrm{~B}, 6 \mathrm{~A}, 7 \mathrm{C}$ e $8 \mathrm{D}$

$1 \mathrm{~A}, 2 \mathrm{D}, 3 \mathrm{~A}, 4 \mathrm{~B}, 5 \mathrm{C}, 6 \mathrm{~B}, 7 \mathrm{D}$ e $8 \mathrm{C}$

$1 \mathrm{D}, 2 \mathrm{C}, 3 \mathrm{C}, 4 \mathrm{C}, 5 \mathrm{~A}, 6 \mathrm{D}, 7 \mathrm{~A}$ e $8 \mathrm{~B}$

$1 \mathrm{~B}, 2 \mathrm{~B}, 3 \mathrm{D}, 4 \mathrm{~A}, 5 \mathrm{D}, 6 \mathrm{C}, 7 \mathrm{~B}$ e $8 \mathrm{~A}$

\section{ESTILO MOTIVACIONAL}

Altamente controlador (AC)

Moderadamente controlador (MC)

Moderadamente promotor de autonomia (MA)

Altamente promotor de autonomia (AA)
Número de itens para cada estilo motivacional

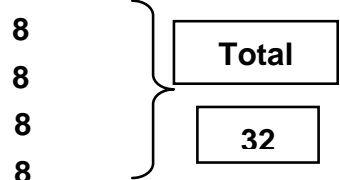

Figura 3. Categorização dos estilos motivacionais analisados referentes à cada vinheta.

Algumas considerações foram feitas aos professores pesquisados antes da aplicação do questionário, a fim de esclarecer qualquer dúvida e evitar a perda de informações que pudessem comprometer a análise dos dados: a) a forma correta de responder o instrumento, não podendo deixar nenhuma questão sem resposta e b) a garantia de sigilo ${ }^{1}$ dos sujeitos.

A categorização dos dados se deu como representado no quadro 1 , ou seja, realizamos o agrupamento das questões referentes a cada estilo motivacional dentro do continuum proposto

\footnotetext{
${ }^{1}$ Todos os professores pesquisados foram informados sobre a divulgação e publicação dos dados coletados, aprovado pelo Comitê Permanente de Ética em Pesquisa em Seres Humanos - Parecer no 175/2007 (Universidade Estadual de Maringá).
} 
(AC, MC, MA e AA). Para a análise dos dados foram seguidas as recomendações de Bzuneck $e$ Guimarães (2007), que sugerem o somatório da freqüência de respostas referentes a cada estilo motivacional relacionado às vinhetas analisadas (Quadro 1). Sendo assim, foi realizada a média das respostas para cada grupo de vinhetas, resultando no estilo motivacional mais adotado pelos professores de educação física.

\section{Resultados e discussões}

Buscando subsídios para analisar o estilo motivacional mais adotado por professores de educação física atuantes na educação infantil e primeiro ciclo do ensino fundamental foram utilizados os conceitos abordados pela teoria da autodeterminação, que se preocupa, principalmente, com o significado dos estímulos, e não com as suas características. Sabe-se que o comportamento humano é derivado de uma série de situações e contextos, e também das necessidades intrínsecas e impulsos psicológicos, os quais produzem energia para o organismo agir no ambiente e gerenciar seus instintos e emoções.

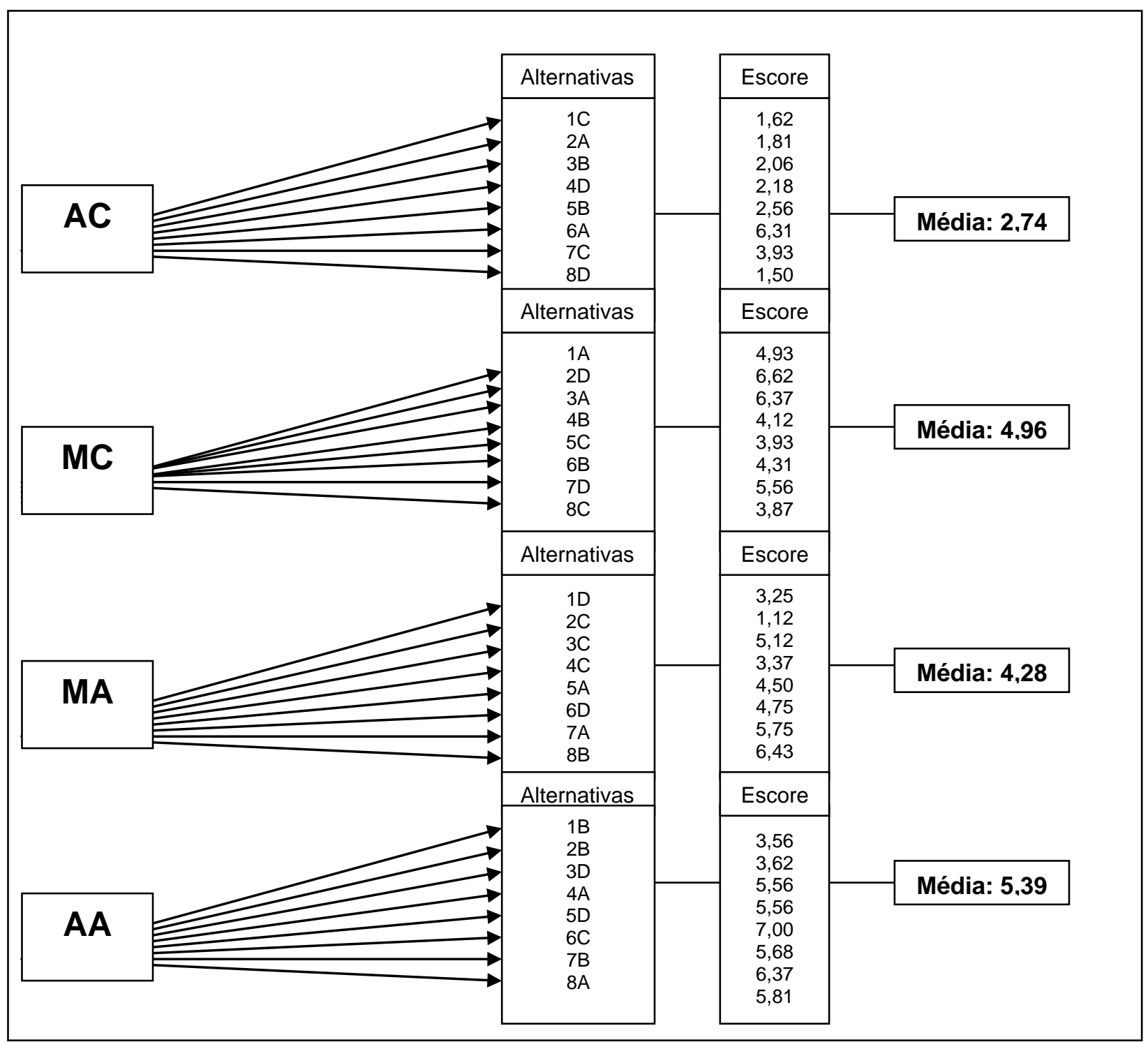

Figura 4. Análise descritiva das variáveis. Cada 'número' no quadro das alternativas representa uma vinheta e as 'letras' representam o grupo de respostas referentes a um dos 4 estilos motivacionais avaliados (AC, MC, MA e AA). Os escores são as médias obtidas por meio do somatório da freqüência de respostas de cada vinheta (32 valores).

As primeiras pesquisas comportamentais apontavam que o estímulo oferecido pelo ambiente não era a causa do comportamento, mas sim, uma oportunidade ou meio para satisfazer as necessidades humanas, tais como fome e sede. Entretanto em 1959, White (1975 apud DECl; RYAN, 2000) ampliou o conceito revelando que as pessoas se envolvem em determinada atividade pela busca pessoal de eficácia e competência. Anos depois, em 1968, 
deCharms (1984 apud DECl e RYAN, 2000) sugeriu que as ações de uma pessoa podem ter tanto um lócus de causalidade interna (intrínseco) como um lócus de causalidade externa (extrínseco). Embora em ambas situações o indivíduo realize a tarefa, a diferença está na origem desse comportamento, uma vez que este intrinsecamente motivado é resultado da necessidade humana de autodeterminação, pois "as pessoas seriam naturalmente propensas a realizar uma atividade por acreditarem que 0 fazem por vontade própria, porque assim 0 desejam" (GUIMARÃES, 2005, p. 2).

Em contrapartida, o lócus de causalidade externa implica em outro agente que interfere na origem do comportamento, levando a pessoa a acreditar que sua ação é mediada por pressões externas, sendo, por exemplo, fruto de um sistema de recompensas e punições: "ao sentirse obrigado por fatores externos a realizar algo, o indivíduo tem sua atenção desviada da tarefa, prejudicando assim a motivação intrínseca" (GUIMARÃES, 2005, p. 2).

A figura 4 aponta as médias obtidas pelos professores pesquisados na avaliação dos quatro estilos motivacionais. Observa-se que a média mais baixa $(2,74)$ foi encontrada na avaliação do estilo motivacional altamente controlador (AC) e, a média mais alta $(5,39)$ foi para o estilo altamente promotor de autonomia (AA).

O estilo motivacional promotor de autonomia evidencia a necessidade psicológica básica de autonomia, designando um ser humano que possui iniciativa na definição de suas ações e na tomada de decisão (Guimarães e Boruchovitch, 2004). Em outras palavras, um indivíduo autônomo é aquele que se torna o regulador de seus comportamentos sem ser altamente ou unicamente influenciado por pressões externas (STANDAGE; DUDA; NTOUMANIS, 2003).

É importante ressaltar que o conceito de autonomia abordado pela teoria da autodeterminação não está relacionado com o individualismo, "mas refere-se a percepção pessoal sobre a origem da ação" (BZUNECK; GUIMARÃES, 2007, p. 416). Em decorrência de situações em que 0 indivíduo tem fortes sentimentos de causa pessoal (lócus interno), ele apresenta um comportamento intrinsecamente motivado: "fixa metas pessoais, demonstra seus acertos e dificuldades, planeja as ações necessárias para viabilizar seus objetivos e avalia adequadamente seu pregresso" (GUIMARÃES, 2005, p.2).

Em contextos educativos, os professores que apresentam atitudes promotoras de autonomia agem nutrindo as necessidades psicológicas básicas de seus alunos, especialmente nos aspectos de segurança e de competência. Ntoumanis (2001) aponta que os estudantes se sentem competentes quando seus professores de educação física enfatizam $o$ progresso no processo de ensino-aprendizagem com base em padrões individuais, não estabelecendo comparações com outros estudantes. Portanto, os estudantes que se percebem competentes têm menores chances de se sentir externamente motivados e de apresentarem comportamentos desmotivados.

Entretanto, para que isso ocorra, os professores precisam oferecer oportunidades de escolhas e feedback significativos aos alunos, ou seja, avaliar o esforço ao invés da habilidade, enfatizar a aprendizagem individual em detrimento da coletiva, reconhecer as dificuldades e oferecer apoio (KOKA; HEIN, 2003; GUIMARÃES; BORUCHOVITCH, 2004). Especificamente nas aulas de educação física, percebe-se um maior engajamento e persistência na tarefa quando os alunos realizam atividades em grupos e dependem uns dos outros para cumprir os objetivos propostos. O ambiente cooperativo também aumenta a afetividade entre as pessoas, alimentando a sua necessidade de estabelecer vínculos pessoais (NTOUMANIS, 2001).

Em um recente estudo, Vierling, Standage e Treasure (2007) sugerem que um ambiente promotor de autonomia aumenta as chances de engajamento dos alunos em atividades físicas, além de apresentarem atitudes positivas perante o exercício. Esse apontamento configura-se como uma importante descoberta para a sociedade contemporânea, pois sabe-se do aumento do número de pessoas que apresentam doenças relacionadas a hábitos de vida pouco saudáveis (MURCIA; COLL, 2006, WILSON ET al., 2006).

Outrossim, quando um aluno tem conhecimento acerca dos objetivos de uma tarefa, bem como as suas normas e formas de avaliação, maiores são as possibilidades do indivíduo alcançar um estado ótimo de motivação 
intrínseca ou caminhar no continuum, se aproximando das formas auto-reguladoras de motivação extrínseca (integrada, identificada, introjetada e externa). Em outras palavras, ambientes informativos favorecem a compreensão dos alunos com relação às razões e objetivos pretendidos com uma determinada tarefa, aumentando as chances de envolvimento dos estudantes no processo de ensinoaprendizagem e de progresso nos níveis de motivação (KOKA; HEIN, 2003).

Em contrapartida, os professores que confiam em um estilo controlador estabelecem para seus alunos "formas específicas de comportamentos, sentimentos ou de pensamentos, oferecendo incentivos extrínsecos e conseqüências para aqueles que se aproximam do padrão esperado" (GUIMARÃES; BORUCHOVITCH, 2004, p. 148).

Nessas situações, a origem do comportamento é a regulação externa, que de acordo com Ntoumanis (2001) sobressai-se em situações nas quais o indivíduo realiza a atividade como forma de obter benefícios ou recompensas de qualquer natureza. Esse é um exemplo de reforçamento clássico do comportamento.

Desse modo, estudar os estilos motivacionais adotados por professores de educação física se configura como um fator importante para a área, porque segundo Régio e Júnior (2007) tanto nas escolas públicas como privadas têm-se observado uma diminuição do incentivo à participação dos alunos nas aulas. Para Bidutte (2001) e Darido (2004) diferentes motivos podem desencadear esse crescente desinteresse: a falta de materiais e instalações adequadas, a carência de profissionais capacitados e envolvidos, posturas excludentes adotadas pelos próprios professores, conteúdos e estratégias de aulas repetitivas e, problemas sociais e familiares. Nessa mesma direção, Silva et al. (2007, p. 71) afirmam que em grande parte das escolas brasileiras "as aulas servem como momento de descanso e de contrapeso às outras disciplinas. Muitos dos professores se acomodaram, alguns por simples conformismo, outros por despreparo ou más condições de trabalho".

As conseqüências imediatas dessa falta de valorização da prática docente para a educação física é que ela "torna-se uma disciplina obsoleta e desinteressante, levando à evasão, sobretudo dos alunos das últimas séries do ensino fundamental e de todo o ensino médio" (ULASOWICZ; PEIXOTO, 2004, p.64). Em decorrência, a disciplina que poderia ser impactante na vida de seus alunos, muitas vezes, acaba por não fazê-lo, haja vista que para concretizar essa função necessita promover em seus alunos o interesse pela aprendizagem e, para tanto, a figura do professor motivado é essencial.

Todavia, concordamos com André (2000) que os problemas das escolas brasileiras vão muito além da motivação de professores e alunos. As escolas em nosso país enfrentam hoje problemas que podem se tornar fontes de pressões externas que prejudicam a motivação dos professores, tais como: a inadequação de instalações, equipamentos e materiais, salas superlotadas, professores com baixos salários e grande carga horária de trabalho, a insuficiência de investimentos e de organização do governo, violência, etc. (TOKUYOCHI ET AL, 2008; ALBERNAZ; FERREIRA; FRANCO, 2002).

Associado a essa realidade, as reformas ocorridas no sistema educativo nos últimos anos, tentando conferir maior qualidade a educação acaba obrigando o professor a conviver com as pressões exercidas pela direção, pelos pais e pelos próprios alunos. Em um estudo publicado por Taylor, Ntoumanis e Standage (2008), os professores de educação física relataram que as pressões exercidas pelo sistema educativo, como a avaliação da sua própria intervenção, a restrição no tempo e a obrigatoriedade de utilização de métodos específicos nas aulas, os obrigam a utilizar estratégias mais controladoras e, portanto, menos motivadoras.

Contudo, ao contrário dos autores, os dados encontrados no presente estudo permitem-nos inferir que os professores pesquisados parecem sentir as pressões exercidas pelo sistema escolar de forma moderada. Isso pode ser explicado por dois motivos: a) ou os professores não sofrem pressões significativas, a ponto de modificarem as suas estratégias de ensino, b) ou eles não atribuem aspectos negativos às pressões externas sofridas.

Neste sentido, os professores de educação física que apresentaram estilo motivacional promotor de autonomia, ou seja, que tem uma motivação interna prevalente, mostram que são capazes de discriminar as pressões externas e 
tem grandes chances de concretizarem uma ação docente que possua uma dimensão inovadora (BEHRENS, 1999).

Essa diferença de comportamento e de atitude é evidente entre os professores conservadores e os professores inovadores, pois além de serem altamente confiantes em suas ações, sentem grande necessidade de autonomia e de êxito.

No entanto, da mesma maneira que os professores, os alunos também enfrentam pressões no cotidiano escolar que podem fortalecer ou prejudicar sua motivação para a aprendizagem, como por exemplo: prazos, notas, regras e comparações (GUIMARÃES, 2005). Na tentativa de minimizar essas pressões, Woolfolk (2000, apud GUIMARÃES, 2005) alerta que o professor deve limitar 0 uso de mensagens controladoras e oferecer informações que fortaleçam a percepção de competência no aluno.

Assim como no estudo de Taylor, Ntoumanis e Standage (2008), os estilos moderadamente promotor (MA) e moderadamente controlador de autonomia (MC) apresentaram médias bastante próximas, pois as diferenças entre um estilo e outro se mostram bastante sutis (Figura 2). Como essas diferenças estão relacionadas à percepção dos professores sobre sua motivação, elas revelam que os docentes podem estar se movendo entre as formas auto-reguladas do continnum da teoria da autodeterminação, dependendo de como suas necessidades estão sendo atendidas.

O estilo moderadamente promotor da autonomia, que apresentou média de 4,28 , pode ser exemplificado em situações que encorajam os alunos a ter empatia pela forma de compreensão, diagnóstico e solução de problemas adotados pelo professor, exigindo um esforço para que o indivíduo faça uma comparação entre a regulação docente e seus próprios valores (GUIMARÃES et al., 2003). Já o estilo moderadamente controlador de autonomia, com média de 4,96, revela um panorama no qual o professor identifica a solução de um problema e encoraja o aluno a realizá-la, porém, apela para o sentimento de culpa para obter resultados. Isso mostra que o professor pode se encontrar em níveis regulatórios de motivação mais próximos da amotivação (regulação externa e introjetada).

Concordamos com Pereira e Moreira (2005) e Júnior (2000) que existe uma grande responsabilidade por parte dos professores de educação física em elaborar um planejamento dinâmico, que atenda às necessidades e interesses dos alunos, aliando os conteúdos à realidade, sem adotar modismos. Não obstante, além do dinamismo que o trabalho exige, torna-se necessário um maior envolvimento e comprometimento por parte dos professores no processo ensino-aprendizagem, lançando mão de estratégias didáticas que possam contribuir na motivação às aulas, promovendo atitudes de autonomia em seus alunos.

\section{Considerações finais}

O desenvolvimento deste estudo possibilitounos alcançar o objetivo inicialmente proposto pela pesquisa, de identificar qual o estilo motivacional adotado por professores de educação física escolar, exclusivamente no que se refere à autonomia.

O estilo motivacional mais utilizado foi o altamente promotor de autonomia e o que apresentou menor média foi 0 altamente controlador. A hipótese conceitual inicial era que o estilo motivacional controlador seria o mais adotado pelos professores, devido a metodologia tradicional de aula, com punições e recompensas, ainda ser utilizada como estratégia de obtenção do controle da turma (disciplina) e conquista de resultados pelos professores. Porém, os resultados não sustentaram essa hipótese, evidenciando o processo positivo das mudanças na formação de professores, fruto de reflexões, estudos e reformulações curriculares dos últimos 20 anos, que vem alterando a maneira de pensar e fazer a educação física escolar.

Todavia, é contraditório afirmar que a maioria dos professores apresenta um estilo motivacional promotor de autonomia, na medida em que acompanhamos a crescente evasão dos estudantes nas aulas de educação física. Acreditamos que, apesar das importantes mudanças curriculares na educação e na própria educação física escolar, com a inserção e ampliação de novos conteúdos, ainda se percebe limitações na prática pedagógica dos professores, pois falta conhecimento de estratégias que promovam o sentimento de autonomia nos estudantes.

As pressões do trabalho e do sistema escolar, no nosso ponto de vista, não foram percebidas pelos professores como fatores determinantes ou 
complicadores de sua intervenção. Não obstante, salientamos que, embora os dados revelem uma atitude autônoma dos professores, o instrumento utilizado tem como foco de análise o estilo motivacional de professores, e não a interferência de pressões externas, pois não é a finalidade do mesmo.

Gostaríamos de destacar que, para confrontar se os estilos motivacionais investigados correspondem realmente às estratégias e atitudes apresentadas pelos professores em suas aulas, faz-se necessário a utilização de outros instrumentos. Além disso, sugerimos estudos futuros que avaliem se a percepção que os alunos possuem acerca dos estilos motivacionais adotados por seus professores representa o mesmo estilo adotado por esses profissionais.

Por fim, constatamos que o estilo motivacional promotor da autonomia, além de ser o estilo mais adotado pelos professores, é também a melhor estratégia a ser adotada nas aulas de educação física de modo a concretizar uma prática docente na educação física escolar que promova efetivamente a aprendizagem. Contudo, os professores de educação física deveriam se atentar ao estilo motivacional adotado em suas aulas, pois o comportamento de seus alunos será fruto da maneira como ele estabelece suas estratégias de ensino-aprendizagem, sendo essa influência positiva ou negativa.

\section{Referências}

ALBERNAZ, A.; FERREIRA, F. H. G.; FRANCO, C. Qualidade e eqüidade no ensino fundamental brasileiro. Pesquisa e planejamento econômico, Rio de Janeiro, v.32, n.3, p. 453476, 2002.

ANDRÉ, M. E. D. A. Etnografia da prática escolar. 5. ed. Campinas: Papirus, 2000.

BETTI, M.; ZULIANE, L. R. Educação Física escolar: uma proposta de diretrizes pedagógicas. Revista Mackenzie de Educação Física e Esporte: São Paulo, v. 1, n. 1, p.73-81, 2002.

BEHRENS, M. A. O paradigma emergente e a prática pedagógica. Curitiba: Champagnat, 1999.

BIDDLE, S.; SOOS, I.; CHATZISARANTIS, N. Predicting physical activity intentions using goal perspectives and self-determination theory approaches. European Psychologist, v.4, n.2, p.83-89, 1999.
BIDUTTE, L. C. Motivação nas aulas de educação física em uma escola particular. Psicologia Escolar e Educacional, v.5, n.2, p.49-58, 2001.

BZUNECK, J. A.; GUIMARÃES, S. E. R. Estilos de Professores na Promoção da Motivação Intrínseca: Reformulação e Validação de Instrumento. Psicologia: Teoria e Pesquisa, v.23, n.4, p.415-422, 2007.

DARIDO, S. C. A Educação Física na escola e o processo de formação dos não praticantes de atividade física. Revista Paulista de Educação Física: São Paulo, v. 18, n. 1, p. 44-58, 2004.

DECI, E. L.; SCHWARTZ, A. J.; SHEINMAN, L.; RYAN, R. M. An instrument to assess adults' orientations toward control versus autonomy with children: reflections on intrinsic motivation and perceived competence. Journal of Educational Psychology, v.73, n.5, p.642-650, 1981.

DECI, E. L.; RYAN, R. M. Intrinsic motivation and self-determination in human behavior. Nova York: Plenum, 1985.

DECI, E. L.; RYAN, R. M. The "what" and "why" of goal pursuits: Human needs and the selfdetermination of behaviour. Psychological Inquiry, v.11, n.4, p.227-268, 2000.

FERNANDES, H. M.; VASCONCELOS-RAPOSO, J. Continuum de auto-determinação: validade para a sua aplicação no contexto esportivo. Estudos de Psicologia, v.10, n.3, p.385-395, 2005.

GUIMARÃES, S. E. R. O estilo motivacional de professores: um estudo exploratório. In: $28^{\text {a }}$ reunião da ANPED, Caxambu. Anais do 28a reunião da ANPED, 2005, p. 1-15.

GUIMARÃES, S. E. R.; BORUCHOVITCH, E. O Estilo Motivacional do Professor e a Motivação Intrínseca dos estudantes: Uma Perspectiva da Teoria da Autodeterminação. Psicologia:

Reflexão e Crítica, v.17, n.2, p.143-150, 2004.

GUIMARÃES, S. E. R.; BZUNECK, J. A.; BORUCHOVITCH, E. Estilos motivacionais de professores: propriedades psicométricas de um instrumento de avaliação. Psicologia: Teoria e Pesquisa, v.19, n.1, p.17-24, 2003.

JÚNIOR. J. M. O professor de educação física e a educação física escolar: como motivar o aluno? Revista da Educação Física /UEM: Maringá, v.11, n.1, p.107-117, 2000.

KOKA, A. HEIN, V. Perceptions of teacher's feedback and learning environment as predictors of intrinsic motivation in physical education. 
Psychology of Sport and Exercise, v. 4, p.333346, 2003.

MURCIA, J. A. M.; COLL, D. G. A. A permanência de praticantes em programas aquáticos baseada na Teoria da Autodeterminação. Fitness \& Performance Journal, Rio de Janeiro, v.5, n.1, p.5-10, 2006.

NTOUMANIS, N. A self-determination approach to the understanding of motivation in physical education. British Journal of Educational Psychology, v.71, p.225-242, 2001.

NTOUMANIS, N. A prospective study of participation in optional school physical education using a self-determination theory framework. Journal of Educational Psychology, v.97, n.3, p.444-453, 2005.

PEREIRA, R. S.; MOREIRA, E. C. A participação dos alunos do ensino médio em aulas de Educação física: algumas considerações. Revista da Educação Física/UEM: Maringá, v.16, n.2, p.121-127, 2005.

RÉGIO, A. R.; JÚNIOR, J. M. Estudo sobre o estilo de ensino desenvolvido por professores nas aulas de educação física em escolas públicas e privadas de Maringá - Paraná. Iniciação Científica CESUMAR, v.09, n.02, p.103-107, 2007.

SILVA, R. B.; OLIVEIRA, A. A. B.; LARA, L. M.; RINALDI, I. P. B. A educação física escolar em Maringá: experiências de ensino-aprendizagem no cotidiano das aulas. Revista Brasileira de Ciências do Esporte: Campinas, v. 28, n. 2, p. 69-83, jan. 2007.

STANDAGE, M.; DUDA, J. L.; NTOUMANIS, N. A model of contextual motivation in physical education: using constructs from selfdetermination and achievement goal theories to predict physical activity intentions. Journal of Educational Psychology, v.95, n.1, p.97-110, 2003.

TAYLOR, I. M.; NTOUMANIS, N.; STANDAGE, M. A Self-Determination Theory Approach to Understanding the Antecedents of Teachers' Motivational Strategies in Physical Education. Journal of Sport \& Exercise Psychology, v.30, p.75-94, 2008.

TOKUYOCHI, J. H. et al. Retrato dos professores de Educação Física das escolas estaduais do estado de São Paulo. Motriz: Rio Claro, v.14, n.4, p.418-428, 2008.

ULASOWICZ, C.; PEIXOTO, J. R. P.

Conhecimentos conceituais e procedimentais na Educação Física escolar: a importância atribuída pelo aluno. Revista Mackenzie de Educação Física e Esporte, n. 3, p.63-74, 2004,

VIERLING, K.; STANDAGE, M; TREASURE, D. Predicting attitudes and physical activity in an "at risk" minority youth sample: a test of selfdetermination theory. Psychology of Sport and Exercise, v.8, p.795-817, 2007.

WILSON, P.; ROGERS, W. T.; RODGERS, W. M.; WILD, T. C. The psychological need satisfaction in exercise scale. Journal of Sport \& Exercise Psychology, v. 28, p.231-251, 2006.

Agradecimento: Gostaríamos de agradecer ao Prof. Dr. José Aloyseo Bzuneck pelos esclarecimentos iniciais sobre $\mathrm{o}$ instrumento de coleta de dados utilizado nesse estudo e pela explicação cuidadosa em relação aos procedimentos que deveríamos adotar para a análise dos dados. Gostaríamos de agradecer também à Prof ${ }^{\mathrm{a}}$. Dr ${ }^{\mathrm{a}}$. Jeane Barcelos Soriano pela cuidadosa leitura e contribuição no texto final deste artigo.

\author{
Endereço: \\ Daniela Schwabe Minelli \\ Rua Pará, 845 Centro \\ Londrina PR Brasil \\ 86001-970 \\ e-mail: daniminelli@onda.com.br
}

Recebido em: 24 de julho de 2009.

Aceito em: 26 de abril de 2010.

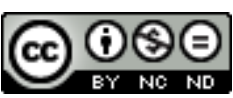

Motriz. Revista de Educação Física. UNESP, Rio Claro, SP, Brasil - elSSN: 1980-6574 - está licenciada sob Licenca Creative Commons 


\section{Anexo 1 \\ Questionário "Problemas na escola" validado Bzuneck et al. (2007)}

\section{Questionário sobre Problemas na Escola ${ }^{2}$}

Nas próximas páginas você encontrará uma série de situações. Cada uma delas descreve um incidente $e$, em seguida, apresenta quatro maneiras diferentes de resolvê-lo. Por favor, leia cada caso e considere cada opção de resposta. Pense o quanto as opções são apropriadas para lidar com o problema apresentado. Você pode achar uma das opções "perfeita" ou, em outras palavras, "extremamente apropriada" e, nesse caso, faça um círculo no número 7 . Você pode considerar uma opção "completamente imprópria" e então circule o número 1 . Caso você considere uma opção "razoável", circule algum número entre 1 e 7. Por favor, avalie cada uma das quatro opções apresentadas para cada caso e assinalea na escala que o acompanha. Há oito casos com quatro opções de resposta para cada um deles. Não há respostas certas ou erradas para essas situações. Os estilos das pessoas são diferentes e estamos interessados em saber o que você considera apropriado, tendo-se em vista o seu próprio estilo.

Algumas histórias indagam o que você faria como professor. Outras solicitam que você responda como se fosse dar um conselho para um outro professor ou para um pai de aluno. Algumas requerem que você responda como se você fosse um pai de aluno. Se você não é mãe ou pai ainda, simplesmente imagine como seria para você essa situação.

Por favor, para responder, faça um círculo, na escala, no número que corresponde à opção que você escolheu para cada situação.

1. Luiz é um aluno médio, com desempenho ao nível de sua classe. Entretanto, nas duas últimas semanas, ele parece desatento, apático e não tem participado do grupo de leitura. O trabalho que faz é bem feito, mas ele não tem completado as tarefas. Uma conversa pelo telefone com a mãe dele não trouxe informações úteis. A coisa mais apropriada para a professora de Luiz fazer é:

a) Acentuar para ele a importância de terminar suas tarefas porque ele precisa aprender esse conteúdo para o seu próprio bem

$\begin{array}{llllllr}1 & 2 & 3 & 4 & 5 & 6 & 7 \\ \text { Muito } & \text { moderadamente } & \text { muito impróprio } & \text { apropriado } & \text { apropriado }\end{array}$

b) Conversar com ele sobre como ele percebe a escola e sobre quais são os motivos que o levaram a diminuir seu interesse pelas atividades de aprendizagem

$\begin{array}{lcccccr}1 & 2 & 3 & 4 & 5 & 6 & 7 \\ \text { Muito } & \text { moderadamente } & \text { muito impróprio } & \text { apropriado } & \text { apropriado }\end{array}$

c) Nunca permitir que ele saia da sala de aula enquanto não tiver terminado as tarefas solicitadas
$\begin{array}{llllllr}1 & 2 & 3 & 4 & 5 & 6 & 7 \\ \text { Muito } & \text { moderadamente } & \text { muito } & \text { impróprio } & \text { apropriado } & \text { apropriado }\end{array}$

${ }^{2}$ Este questionário foi elaborado e validado por Bzuneck e Guimarães (2005). O trabalho de pesquisa e validação do instrumento contou com apoio da CNPq - Processo $n$. 401752/2003-8. d) Contar para ele que, quando tinha sua idade, também não entendia a importância das aulas e tarefas, mais tarde entendeu e teve que estudar mais para recuperar o tempo perdido

$$
\begin{array}{lccclll}
1 & 2 & 3 & 4 & 5 & 6 & 7 \\
\text { Muito } & \text { moderadamente } & \text { muito impróprio } & \text { apropriado } & \text { apropriado }
\end{array}
$$

2. Em uma reunião de pais na noite passada, o Sr. e a Sra . Silva foram informados que sua filha Sarah havia progredido mais nas atividades escolares do que era esperado, desde a última reunião. Todos acreditam que ela continuará melhorando e que não deve ser retida na série (era o que os pais estavam esperando desde que receberam o último boletim). Como resultado da reunião, os pais de Sarah decidem:

a) Premiá-la e prometer-Ihe um prêmio especial se ela continuar melhorando

$\begin{array}{lrrrlll}1 & 2 & 3 & 4 & 5 & 6 & 7 \\ \text { Muito } & \text { moderadamente } & \text { muito impróprio } & \text { apropriado } & \text { apropriado }\end{array}$

b) Dizer que estão alegres com a sua conquista porque acreditam que o sucesso na escola depende dela mesma

$\begin{array}{lllllll}1 & 2 & 3 & 4 & 5 & 6 & 7 \\ \text { Muito } & \text { moderadamente } & \text { muito impróprio } & \text { apropriado } & \text { apropriado }\end{array}$

c) Falar com ela sobre o seu progresso mostrando que eles sabem que ela está se tornando cada vez mais independente na escola e em casa
$\begin{array}{lccc}1 & 2 & 3 & 4 \\ & & 5 & \end{array}$
$5 \quad 6 \quad 7$

d) Continuar enfatizando que ela tem que estudar bastante para conseguir notas melhores

$\begin{array}{lllllll}1 & 2 & 3 & 4 & 5 & 6 & 7 \\ \text { Muito } & \text { moderadamente } & \text { muito impróprio } & \text { apropriado } & \text { apropriado }\end{array}$

3. Daniel quase não se controla em sala de aula e acaba agitando outras crianças. Ele não dá a menor atenção quando você diz que está preocupado (a) porque você acha que ele não vai aprender as habilidades sociais que ele necessita. A melhor coisa que você deve fazer com ele é:

a) Enfatizar o quanto é importante ele se controlar para se sair bem na escola e em outras situações

$\begin{array}{lllllll}1 & 2 & 3 & 4 & 5 & 6 & 7 \\ \text { Muito } & \text { moderadamente } & \text { muito impróprio } & \text { apropriado } & \text { apropriado }\end{array}$

b) Encaminhá-lo para uma classe especial que tenha a estrutura e as possibilidades de recompensas que ele precisa

$\begin{array}{llrrlll}1 & 2 & 3 & 4 & 5 & 6 & 7 \\ \text { Muito } & \text { moderadamente } & \text { muito impróprio } & \text { apropriado } & \text { apropriado }\end{array}$

c) Contar para ele que na sua vida escolar você também não se comportou bem em algumas aulas e, com isso, perdeu algumas oportunidades interessantes $\begin{array}{lllllll}1 & 2 & 3 & 4 & 5 & 6 & 7 \\ \text { Muito } & \text { moderadamente } & \text { muito impróprio } & \text { apropriado } & \text { apropriado }\end{array}$

d) Perceber que Daniel provavelmente não esteja recebendo a atenção que necessita e começar a dar mais atenção para ele

$\begin{array}{lllllll}1 & 2 & 3 & 4 & 5 & 6 & 7 \\ \text { Muito } & \text { moderadamente } & \text { muito impróprio } & \text { apropriado } & \text { apropriado }\end{array}$

4. Seu filho é um dos melhores jogadores do time de futebol da escola, tendo vencido a maioria dos jogos. Entretanto, você está preocupado (a) porque ele acabou de lhe contar que não foi bem em uma prova de português e terá que refazê-la no dia seguinte. Sabendo que ele tem um jogo 
marcado e que precisará estudar, você decide que a melhor coisa a fazer é:

a) Pedir a ele que the conte sobre os seus planos para lidar com a situação

$\begin{array}{lcccllr}1 & 2 & 3 & 4 & 5 & 6 & 7 \\ \text { Muito } & \text { moderadamente } & \text { muito impróprio } & \text { apropriado } & \text { apropriado }\end{array}$

b) Lembrá-lo de que todos esperam que ele se saia bem na escola e caso ele não abra mão do jogo para estudar irá se sentir mal

$\begin{array}{lccclll}1 & 2 & 3 & 4 & 5 & 6 & 7 \\ \text { Muito } & \text { moderadamente } & \text { muito impróprio } & \text { apropriado } & \text { apropriado }\end{array}$

c) Mostrar que você sabe o quanto o jogo de futebol é importante para ele, mas que acredita que ele saiba o quanto é importante escrever bem o português

$\begin{array}{lllllll}1 & 2 & 3 & 4 & 5 & 6 & 7 \\ \text { Muito } & \text { moderadamente } & \text { muito impróprio } & \text { apropriado } & \text { apropriado }\end{array}$

d) Fazer com que ele falte o jogo para estudar; o futebol tem interferido demais com o seu desempenho escolar

$\begin{array}{lllllll}1 & 2 & 3 & 4 & 5 & 6 & 7\end{array}$

Muito moderadamente muito impróprio apropriado apropriado

5. Nas aulas de reforço de matemática a professora Raquel não tem notado progresso no desempenho de seus alunos. Se você estivesse no lugar dela o que faria para ajudá-los?

a) Conversaria com eles sobre suas dificuldades demonstrando que acredito que se esforçarão para melhorar

$\begin{array}{lllllll}1 & 2 & 3 & 4 & 5 & 6 & 7 \\ \text { Muito } & \text { moderadamente } & \text { muito impróprio } & \text { apropriado } & \text { apropriado }\end{array}$

b) Faria com que praticassem mais e daria privilégios especiais pelos seus progressos

$\begin{array}{lllllll}1 & 2 & 3 & 4 & 5 & 6 & 7\end{array}$

c) Mostraria ao grupo os erros que cometeram com mais freqüência e insistiria para que eles se esforçassem mais

$\begin{array}{llllll}2 & 3 & 4 & 5 & 6 & 7 \\ \text { moderadamente } & \text { muito impróprio } & \text { apropriado } & \text { apropriado }\end{array}$

Muito moderadamente muito impróprio apropriado apropriado

d) Ajudaria o grupo a desenvolver maneiras de aprender juntos (jogos, dramatizações, etc.)

$\begin{array}{lllllll}1 & 2 & 3 & 4 & 5 & 6 & 7\end{array}$

6. Em sua classe, há uma menina chamada Margarida que tem sido alvo de zombarias. Ela é quieta e quase sempre está sozinha. Apesar dos esforços de professores anteriores, ela não é aceita pelas crianças. Seu bom senso the conduziria a:

a) Dizer-lhe que deve aproximar-se dos colegas e elogiá-la quando agir como você ensinou

$\begin{array}{lllllll}1 & 2 & 3 & 4 & 5 & 6 & 7\end{array}$

b) Dizer a ela que você ficaria satisfeito (a) a com a sua aproximação dos colegas e que se frustraria caso ela não se esforçasse para isso

$\begin{array}{lllllll}1 & 2 & 3 & 4 & 5 & 6 & 7\end{array}$

c) Convidá-la a falar sobre suas relações com outras crianças e encorajá-la a dar passos pequenos quando ela se sentir pronta para isso

$\begin{array}{lllllll}1 & 2 & 3 & 4 & 5 & 6 & 7 \\ \text { Muito } & \text { moderadamente } & \text { muito impróprio } & \text { apropriado } & \text { apropriado }\end{array}$ d) Contar-Ihe que todas as pessoas podem se sentir isoladas às vezes, mas que você acredita na sua vontade de aproximar-se dos colegas

$\begin{array}{lllllll}1 & 2 & 3 & 4 & 5 & 6 & 7\end{array}$

Muito moderadamente muito impróprio apropriado apropriado

7. Faz algumas semanas que objetos têm desaparecido da mesa da professora e o dinheiro do lanche de algumas crianças tem sido tirado de suas carteiras. Hoje, Marcos foi visto pela professora retirando de sua mesa um peso de papel prateado. Ela telefonou para a mãe de Marcos e falou sobre o incidente. Embora a professora também suspeite que Marcos seja responsável pelos outros furtos, ela mencionou para a mãe somente este e assegurou a ela que ficaria mais atenta aos comportamentos de Marcos. A melhor coisa para a mãe de Marcos fazer é:

a) Lembrar-Ihe de como ele mesmo se sente quando perde um objeto importante e como as outras pessoas devem ficar aborrecidas por não encontrarem suas coisas

$\begin{array}{lcccllr}1 & 2 & 3 & 4 & 5 & 6 & 7 \\ \text { Muito } & \text { moderadamente } & \text { muito impróprio } & \text { apropriado } & \text { apropriado }\end{array}$

b) Conversar com ele sobre o assunto, expressando sua confiança nele e tentando compreender porque ele fez isso

$\begin{array}{llllllr}1 & 2 & 3 & 4 & 5 & 6 & 7 \\ \text { Muito } & \text { moderadamente } & \text { muito impróprio } & \text { apropriado } & \text { apropriado }\end{array}$

c) Castigá-lo tirando algo que gosta para que aprenda que não pode roubar

$\begin{array}{llllllr}1 & 2 & 3 & 4 & 5 & 6 & 7 \\ \text { Muito } & \text { moderadamente } & \text { muito impróprio } & \text { apropriado } & \text { apropriado }\end{array}$

d) Deixar bem claro que isso foi errado e que ela se sentiria aliviada se ele pedisse desculpas para a professora, além de devolver o objeto

$\begin{array}{lllllll}1 & 2 & 3 & 4 & 5 & 6 & 7 \\ \text { Muito } & \text { moderadamente } & \text { muito impróprio } & \text { apropriado } & \text { apropriado }\end{array}$

8. Seu filho tem obtido notas regulares na escola e você gostaria que ele melhorasse. Uma estratégia adequada seria:

a) Encorajá-lo a falar sobre o seu boletim de notas e sobre o que o mesmo significa para a vida dele
$\begin{array}{lcccccc}1 & 2 & 3 & 4 & 5 & 6 & 7 \\ \text { Muito } & \text { moderadamente } & \text { muito impróprio } & \text { apropriado } & \text { apropriado }\end{array}$

b) Dizer que notas baixas significam que muitos conteúdos não foram aprendidos e poderão fazer falta no futuro

$\begin{array}{lllllll}1 & 2 & 3 & 4 & 5 & 6 & 7 \\ \text { Muito } & \text { moderadamente } & \text { muito impróprio } & \text { apropriado } & \text { apropriado }\end{array}$

c) Ressaltar que ele deve ir melhor e que com notas como estas ele jamais entrará em uma universidade

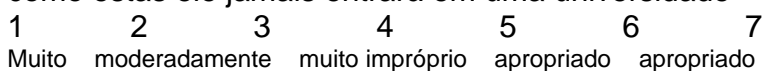

d) Oferecer 1 real por cada conceito A obtido e 50 centavos por cada conceito $B$ nos .próximos boletins

$\begin{array}{lllllll}1 & 2 & 3 & 4 & 5 & 6 & 7\end{array}$ 